\title{
Program Assessment: Not In My Back Yard
}

Lynn Johnson, California State University-Stanislaus, USA

\begin{abstract}
Faculty in the College of Business Administration at California State University-Stanislaus struggled to find places within the curriculum in which to embed programmatic assessment. An assessment model emerged from their discussions that meaningfully assesses the knowledge and skills of graduating seniors for programmatic improvement while providing each student with individualized feedback about their strengths and weaknesses. Students identify those areas in which they are particularly strong, which is useful information during career exploration, along with those areas in which further development would be beneficial. Resources for life-long personal and professional development are provided to participating students.
\end{abstract}

Keywords: Assessment; Program Assessment; Formative Assessment

\section{DEVELOPMENT OF INITIAL PROGRAM ASSESSMENTS}

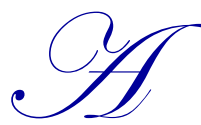

-mong the decisions that academic programs must make when developing an assessment program are when and where assessment data will be gathered. Assessment of individual student performance can, and does, take place a number of times throughout a student's participation in a degree program. Program assessment can be implemented at a variety of times as well: 1) when students initially enter an academic program, 2) at any point during the students' progress towards a degree, or 3) at the end of the students' program of study. Since the purpose of programmatic assessment is to examine "whether the curriculum makes sense in its entirety and whether students, as a result of all their experiences, have the knowledge, skills, and values that graduates should possess [emphasis added]" (Palomba and Banta, 1999, p. 5), the faculty of the College of Business Administration at CSU-Stanislaus determined that a logical point to gather information for assessing their undergraduate program is after a student has completed all of the coursework related to a specific learning objective. Ideally, assessment would take place as near to graduation as possible.

As the College of Business Administration at CSU-Stanislaus began systematic assessment of graduating students, it struggled to find a place where such assessment could take place. While the faculty briefly considered bribing students with offers of pizza or Starbucks gift certificates if they would come to campus for assessment on a Saturday near the end of their final semester, this seemed difficult to operationalize. Also, since the students would be self-selected, faculty members were not certain that a representative sample could be obtained. Consequently, they decided that assessment should take place in the classroom.

The undergraduate B.S. in Business Administration degree at CSU-Stanislaus has only one course that must be taken during the students' final semester in the core undergraduate program - Business Policy - its capstone course. Therefore, the College first attempted to gather all of its assessment evidence in this course. Initial assessment efforts were centered around the Undergraduate Management Education Exit Survey, developed by EBI, and a system-wide Business Assessment Test (BAT) developed by faculty within the California State University System. Each year since 2004-05, the faculty teaching Business Policy have been asked to provide one class session each semester to administer either the BAT or the EBI to their students. This worked reasonably well at first; while every instructor was not able to accommodate the request every semester, the faculty believed the students who were assessed comprised a representative sample of the entire graduating class. 


\section{DIFFICULTIES IN IMPLEMENTING ASSESSMENT ACTIVITIES}

As budgetary constraints have forced class sizes to grow, the capstone instructors have found it more difficult to accommodate the request for class time. Because several Business Policy instructors include student presentations of their culminating projects in the course, additional students have necessitated allotting more time to class presentations. Understandably, these faculty members were not able to provide a class session to be used for program assessment without removing important material from the course.

The college also encountered difficulties as it expanded its assessment efforts beyond student knowledge that can be assessed through objective examinations. As faculty considered how to evaluate student achievement of more subjective skills - communication, problem-solving, and ethical reasoning, for example - they decided that course-embedded assessment methods would provide evidence of student learning most conveniently, since this method makes use of coursework already in place for programmatic assessment. The Undergraduate Assessment Committee talked with the Business Policy instructors to determine if assignments could be identified or created that would provide assessment evidence, rotating through the learning objectives over several semesters in the hope that the instructors would not feel too overloaded in any particular term. The instructors were not asked to assess the student work themselves; other faculty members within in the College performed the actual assessments using rubrics approved by the entire college faculty. However, the Business Policy faculty members did need to evaluate each student's work for purposes of assigning a course grade. Understandably, it did not take too many semesters before the Business Policy instructors objected to carrying the entire assessment load.

For one thing, embedded assessment does not work well in the capstone classes because the policy instructors rely extensively on group projects. They feel that learning to perform effectively in workgroups is a critical objective of their courses; recognizing and playing to the strengths of the individual members of a group is an important component of strategic thinking, one of the key topics covered in the course. Consequently, the written assignments normally collected and graded in those classes all result from group efforts. Since AACSB does not accept group assignments for assessment of most learning objectives, the Business Policy courses, as currently structured, do not provide the college with usable evidence. All but one of the Policy instructors felt that it was not possible to embed an individual assignment without compromising the distinctive nature of their courses and that the time required to grade individual assignments from each student placed an unreasonable burden on them. One of the faculty members did agree to modify his course in the short term to include an assignment specifically designed to provide the evidence needed. His cooperation allowed the College to obtain a sample of students to assess most learning objectives so that accreditation requirements were satisfied, but a better long-term solution was necessary.

The faculty then decided to collect evidence for assessment in other courses, rather than relying only on Business Policy. They were able to identify classes in which appropriate assignments were already part of the curriculum, usually in a class in which the program learning objective was a primary emphasis of the course. In this way, assessment was not an additional burden to the instructor; processes that were already in place could be used for programmatic improvement.

However, if assessment is embedded in the course in which the relevant learning objective is emphasized, the results indicate how well the students mastered the objective immediately after its coverage. Such evidence does not measure the knowledge and skills retained by the students as they transition into the workforce, sometimes several years after completing the class. While important information was obtained from these assessments, the faculty was not comfortable using only these results to assess its program. Students can take all courses in the business core, other than the capstone, in any sequence as either juniors or seniors. Consequently, many students would be assessed before they had progressed halfway through the upper division business program. The College did not believe such assessments provided conclusive evidence about the program as a whole.

The faculty of the College of Business Administration at CSU-Stanislaus decided it was most interested in the knowledge and skills its students took with them when they graduated from the program. Knowledge briefly acquired is of little use if students are not able to recall and use it once they transition into the work force. Faculty agreed upon a body of knowledge considered essential for all graduates and a set of skills that all students should possess when a degree is conferred upon them. In order to understand the extent to which the College meets its learning goals, students must be assessed as near to graduation as possible. 


\section{ADDITIONAL CONCERNS IDENTIFIED}

While considering how best to accomplish assessment, three other issues were being discussed among the faculty. Some faculty members believe program assessment plans should be designed so that the individual students can benefit from the results. Assessment results are aggregated and used to improve the degree program; this, of course, should benefit future students. However, each individual student's assessment results, which measure their progress toward meeting the program learning objectives, are not provided to the students. Faculty members suggested that a wealth of information was being gathered that could be useful to students as they embarked on their careers. An understanding of their individual strengths and weaknesses would allow them to better market themselves and provide direction for future personal growth.

Additionally, college faculty members were aware that many students needed guidance about business etiquette and maintaining a professional presence. "Business etiquette ranks as one of the top three skills lacking among college graduates, according to the National Association of Colleges and Employers' Job Outlook for the Class of 2005" (Bass, 2010, p. 57). Bass goes on to suggest that "it is just as important that colleges of business recognize the importance of this 'hidden curriculum' and teach it as a vital component of their curricula," going so far as to recommend that a course devoted entirely to the subject be added to the undergraduate business curriculum.

For many years, CSU-Stanislaus provided an excellent Career Services Center for students. They were able to participate in mock interviews, obtain personalized assistance with resume preparation, as well as other related services. However, as the University's financial resources have diminished, Career Services has lost personnel and fewer personalized resources are available to students. The College believes that graduating students are less prepared that in the past to successfully identify and obtain a position that aligns with the students' individual skill-sets and interests.

\section{THE RESULT: BUS 4000 -- BUSINESS PROFESSIONALISM}

The faculty of the College of Business Administration at CSU-Stanislaus, developed a course that will allow each of these concerns to be addressed:

1. How can all learning objectives be assessed as students complete the undergraduate degree program?

2. Can information about the performance of individual students obtained through program assessment be utilized for the benefit of each specific student?

3. Can the curriculum be expanded to include professional presence and etiquette?

4. Which services previously offered through the Career Services Center can be included in the business curriculum to assist students in transitioning from the classroom to the workplace?

A one-unit course called Business Professionalism was developed, which will be required of all students during their final semester in the undergraduate program. Assessment measures of all program learning objectives will be gathered through assignments and exams embedded in the class, providing the college with direct evidence of student learning at a time when the students are exiting the program. The course allows students to assess their individual attainment of the knowledge and skills essential for success in business and describes opportunities to further enhance their skill-set during their professional careers. It will provide opportunities and instruction so that students can further develop the interpersonal skills necessary to maintain a professional presence, providing them with information about appropriate etiquette in business. And finally, the course helps the students transition to industry, or back to the workforce following graduation, through preparation of a professional resume and cover letter and the development of effective interview skills.

As part of the course requirements, students will complete individual assignments that provide evidence of their attainment of each of the program learning objectives related to oral and written communication, ethical reasoning, and problem solving skills. The CSU system-wide Business Assessment Test will also be administered in this class. This course will allow us to gather information about all of our students as they graduate that will be aggregated to provide evidence about our program's effectiveness. 
Dixon (1994) identifies common characteristics of three successful higher education assessment models. One of the characteristics is that students are provided with feedback from the process and encouraged to complete self assessments. The individual results of all assessment exercises completed during this course will be provided to the students, so that they have a measure of their progress in developing the knowledge and skills essential to success in business. This information will allow students to emphasize their individual strengths on their resumes and during job interviews. The individualized feedback provided to students will also enable them to better identify job opportunities that are a good match with their skill-sets. According to Addams and Woodbury (2009), research suggests that educators have a responsibility to teach students how to market themselves and search for jobs effectively. "Otherwise good students can get bad jobs, which reflects not only on the students but also on colleges and universities providing business education." (p. 13)

\section{ENCOURAGEMENT OF LIFE-LONG LEARNING}

Throughout the course, students will be provided with information about how to improve their skills and/or knowledge in those areas in which assessment results reveal further development would be beneficial. For example, students whose oral communication skills are not as strong as they would like will be encouraged to join Toastmasters to gain additional experience and feedback in this area. Faculty believe that this information will set the stage for life-long learning - that students will realize that their education is not concluded, but that they are progressing on a path of personal development that will continue throughout their careers (and beyond).

While not one of the original four issues that were the impetus for this course, the faculty of the College of Business Administration believes that a discussion of the opportunities for, and importance of, continuous personal development subsequent to graduation will be an important benefit of this course. According to Sladoljev-Agejev, et. al. (2006), a quality business education should "not only provide students with specific fact-based knowledge, but also equip them for life-long learning, an indispensable career requirement."

\section{CONCLUSION}

We believe this class represents an assessment model that meaningfully evaluates the knowledge and skills of graduating seniors for program improvement, while providing each student with individualized feedback about their strengths and weaknesses, along with resources for life-long personal and professional development.

\section{AUTHOR INFORMATION}

Lynn Johnson is a Professor of Accounting at CSU-Stanislaus, teaching Auditing and Intermediate Accounting. She has coordinated undergraduate assessment in the College of Business Administration since 2003. She has published articles in Accounting Forum, the American Journal of Business Education, and New Accountant, primarily in the area of audit pricing and production costs and assessment. Dr. Johnson can be reached at Ljohnson3@ csustan.edu

\section{REFERENCES}

1. Addams, L. and Woodbury, D., 2009. Teaching Job Search Written and Oral Communication Skills through an Integrated Approach, American Journal of Business Education 2(4): 13 - 18.

2. Bass, A., 2010. From Business Dining To Public Speaking: Tips for Acquiring Professional Presence and Its Role in the Business Curricula, American Journal of Business Education 3(2): 57-63.

3. Dixon, T., 1994. A Discussion of Non-Traditional Outcomes Assessment Models. Paper presented at the Annual National Conference of Academic Deans (48 ${ }^{\text {th }}$, Stillwater, OK, July 24, 1994).

4. Palomba, C. and Banta, T., 1999. Assessment Essentials: Planning, Implementing, and Improving Assessment in Higher Education. San Francisco, CA, Jossey-Bass.

5. Sladoljev-Agejev, T., Bahovec, V., Kurnoga-Zivadinovic, N. and Spiljak, V., 2006. Managing Motivation of Business Students -- A Teaching Strategy and a Path to Life-Long Learning. An Enterprise Odyssey, International Conference Proceedings: 454-466. University of Zagreb (June 15 - June 17, 2006). 